\title{
INGLÊS SEM FRONTEIRAS: UMA MIRADA AO CONTEXTO DE PRÁTICA PELO PRISMA DA FORMAÇÃO DE PROFESSORES
}

\section{ENGLISH WITHOUT BORDERS: A GLANCE AT THE CONTEXT OF PRACTICE THROUGH THE PRISM OF TEACHER DEVELOPMENT}

\author{
Simone Sarmento* \\ Universidade Federal do Rio Grande do Sul \\ Porto Alegre, RS, BR \\ William Kirsch ${ }^{* *}$ \\ Universidade de Rio Grande \\ Rio Grande, RS, BR
}

\begin{abstract}
Resumo
O Programa Inglês sem Fronteiras (agora Idiomas sem Fronteiras - IsF) é uma política pública que foi primeiramente pensada para oferecer cursos de inglês de modo a capacitar os estudantes elegíveis ao Ciência sem Fronteiras a estudarem em universidades estrangeiras. Entretanto, na prática, há um número de outras implicações, ou efeitos, que são visíveis para todos os seus participantes, sendo a formação de professores de língua inglesa umas das principais, pois grande parte dos professores bolsistas do Programa são alunos de licenciatura em Letras. Neste artigo, enfocamos o Núcleo de Língua Inglesa (NucLi) do IsF-UFRGS, do qual 12 professores foram submetidos a um questionário online feito através do Google Forms. Os dados, embora preliminares, mostram que o IsF apresenta-se como um palco para o desenvolvimento de professores com o potencial de integrar reflexão teórica e prática a partir de experiências concretas vivenciadas no trabalho docente.
\end{abstract}

Palavras chave: Inglês sem Fronteiras; Formação de Professores

\begin{abstract}
The English without Borders Program (now Languages without Borders) is a public policy first thought to offer English courses in order to enable Science without Borders eligible students to study in universities abroad. However, in practice, there are a number of other implications or effects, which are visible to all participants, being teachers' development one of them, since most of the teachers are undergraduate students pursuing a teaching degree in English. In this paper, we focus on the Language Center at the Federal University of Rio Grande do Sul, where 12 teachers underwent an online survey through Google Forms. The data, albeit integral to a preliminary study, show that the ISF can be regarded as an important stage for teachers' education integrating theory and practice based on concrete experiences.
\end{abstract}

Keywords: English without Borders; Teacher Development

\footnotetext{
* Simone Sarmento has a Ph.D (Universidade Federal do Rio Grande do Sul, BR) and two MAs (Lancaster University, UK and Universidade Federal do Rio Grande do Sul, BR ) in Language Studies. She is a professor in the Department of Modern Languages at Universidade Federal do Rio Grande do Sul. Her research interests include Teacher Education, Educational Policies and Corpus Linguistics. E-mail: simone.sarmento@ufrgs.br

${ }^{*}$ William Kirsch has an MA (Universidade Federal do Rio Grande do Sul, BR) and is currently pursuing a Ph.D (Universidade Federal do Rio Grande do Sul, BR) in Applied Linguistics. He is a professor at the Institute of Language and Arts at Universidade Federal do Rio Grande. His research interests include Teacher Education, Educational Policies and Internationalization of Higher Education Institutions. E-mail: william_kirsch@yahoo.com.br
} 


\section{Introdução}

Um fotógrafo-artista me disse outra vez: veja que pingo de sol no couro do lagarto é para nós mais importante do que o sol inteiro no corpo do mar. Falou mais: que a importância de uma coisa não se mede com fita métrica nem com balanças nem com barômetros etc. Que a importância de uma coisa há que ser medida pelo encantamento que a coisa produza em nós. Assim um passarinho nas mãos de uma criança é mais importante para ela do que a cordilheira dos Andes. Que o osso é mais importante para o cachorro do que uma pedra de diamante. E um dente de macaco da era terciária é mais importante para os arqueólogos do que a Torre Eiffel.

(Manoel de Barros)

Como nos ensina o sociólogo da educação Stephen Ball e seus colaboradores (BALL, 1994; BOWE, BALL e GOLD, 1992), as políticas públicas voltadas à educação ganham vida nas práticas sociais dos sujeitos que as vivem no seu cotidiano, e não no campo dos grandes Discursos (nacionais e internacionais) que as instanciam e suportam, nem nas esferas públicas de decisão política (infelizmente, ainda, geralmente, muito distantes do cidadão), tampouco nos textos políticos que as materializam (leis, portarias, editais, entre tantos outros). Dito de modo direto: o epicentro de uma política pública são os infinitos cenários da vida cotidiana em que as pessoas conjuntamente constroem o(s) mundo(s) em que vivem e a(s) história(s). Na vida cotidiana, os sujeitos reconstroem as políticas públicas a partir de suas leituras dos documentos políticos, que um dia foram grandes discursos e debates nas nossas diversas instituições oficiais, ainda que esse trabalho cotidiano costume ser pouco descrito e, talvez por isso, pouco visto. Ou seja, o campo mais importante de uma política é paradoxalmente o menos visto: a miudeza do dia a dia, o que valora a escolha de iniciarmos este texto pela singela epígrafe acima e revela a lente que usaremos para tratar da formação de professores no Inglês sem Fronteiras (IsF)! ${ }^{1}$

O programa, inicialmente, tinha por foco preparar os alunos para embarcarem no Ciência sem Fronteiras (CsF), através do estabelecimento de Núcleos de Ensino de Língua Inglesa (os NucLi). No entanto, recentes trabalhos produzidos por pessoas vinculadas aos NucLis vêm apontando um potencial riquíssimo na atuação desses núcleos: a formação de professores de inglês como língua adicional (SARMENTO e KIRSCH, 2014a; SARMENTO e KIRSCH, 2014B; AUGUSTO-NAVARRO e GATTOLIN, 2014; WELP, SARMENTO e KIRSCH 2014; KUERTEN-DELLAGNELO, 2014). Pode-se dizer, inclusive, que essa dimensão de formação de professores passou a integrar o discurso oficial sobre o IsF (cf. ABREU E LIMA, 2014). Desse modo, entendemos o título desta edição como um convite irrecusável para unirmos dois universos que se intersectam nas suas dimensões complexas, multifacetadas e - por que não? - caóticas: as políticas públicas educacionais e a formação de professores.

Assim sendo, este texto visa a relatar um recorte das ações que estão ocorrendo no Núcleo de Ensino de Inglês da Universidade Federal do Rio Grande do Sul (doravante NucLi-UFRGS), focando na formação de professores. Com esse recorte e os dados que temos, podemos adiantar que o IsF tem propiciado aos professores (1) um desenvolvimento profissional por dentro da profissão (NÓVOA, 2009); (2) a partir do trabalho docente e da reflexão sobre esse trabalho (SCHON, 2000); e (3) por meio da participação em comunidades de prática (WENGER, 2000) que propiciam um desenvolvimento profissional conjunto a partir do cotidiano nela vivenciados (COSTA, 2013).

Para tanto, nosso texto seguirá o seguinte percurso: (2) delinearemos o universo teórico-conceitual em que estão ancoradas nossas reflexões, a saber, as reflexões de Nóvoa (2009) sobre a formação docente para o trabalho $^{2}$ e o Ciclo de Políticas de Stephen Ball e colaboradores (BALL, 1994; BOWE, BALL e GOLD, 1992); (3) apresentaremos o NucLi de modo a situar o leitor em nosso setting; (4) apresentaremos os métodos pelos quais os dados foram gerados; (5) analisaremos, de modo sucinto, os dados gerados; e (6) faremos breves considerações sobre alguns dos impactos que pudemos verificar que o IsF, no âmbito do NucLi-UFRGS, tem tido no tocante à formação de professores.

\section{Mosaico teórico-conceitual}

É interessante notar que nosso mosaico teórico e conceitual para a investigação de que deriva este tex- 
to foi construído a partir das demandas propostas pelo próprio objeto investigado: a formação de professores no NucLi-UFRGS. Nossa vivência do NucLi e pequenas investigações pontuais para apresentações em congressos recentes (SARMENTO e KIRSCH, 2014; SARMENTO, KIRSCH e WELP, 2014; WELP, SARMENTO e KIRSCH, 2014) nos fizeram atentar para algumas questões interessantes. Em primeiro lugar, cada NucLi tem suas idiossincrasias, embora pertençam à mesma política. Em segundo lugar, o NucLi-UFRGS tem mapeado efeitos de sua atividade que não estavam previstos na proposta inicial do IsF. Em terceiro lugar, uma dessas questões, a formação de professores, está diretamente vinculada ao trabalho docente ${ }^{3}$ e à vivência desses professores-bolsistas em uma comunidade de prática voltada a quefazeres relativos a nossa profissão e a sua formação. ${ }^{4}$

\subsection{Ciclo de políticas de Ball e colaboradores}

A abordagem do Ciclo de Políticas (do inglês Policy Cycle Approach; doravante, ACP) foi formulada pelo sociólogo inglês Stephen Ball e seus colaboradores (BOWE; BALL; GOLD, 1992; BALL, 1994) e tem se popularizado em vários trabalhos ao redor do mundo (MAINARDES, 2006, p. 48), e em trabalhos da área de Linguística Aplicada (LA) no Brasil. A ACP tem

um referencial analítico útil para a análise de programas e políticas educacionais e [...] permite a análise crítica da trajetória de programas e políticas educacionais desde sua formulação inicial até a sua implementação no contexto da prática e seus efeitos (MAINARDES, 2006, p. 48)

A ACP apresenta cinco contextos (ou arenas) contínuos, não lineares, não sequenciais e sem dimensão estritamente temporal, em permanente influência mútua no decorrer da "vida" de uma política: (1) o contexto de influência, (2) o contexto de produção do texto político, (3) o contexto de prática e (4) o contexto de resultados (efeitos) e o (5) contexto da influência política. ${ }^{5}$ Entretanto, para este trabalho, focaremos nos quatro primeiros. O contexto de influência é constituído pelas arenas em que os discursos políticos são construídos e onde diversos grupos de interesse disputam os regimes de verdade que guiarão as finalidades da educação. É nesse contexto que atuam "as redes sociais dentro e em torno de partidos políticos, do governo de processo legislativo" (MAINARDES, 2006, p. 51). É principalmente nessa arena que os discursos que circulam internacionalmente pelas agendas globais encontram espaço nas agendas locais, isto é, o global e o local se interpenetram e se fortalecem mutuamente (GIDDENS, 1991, p. 76). Um exemplo claro desse fenômeno é o discurso acerca da importância da língua inglesa como $a$ língua das sociedades globalizadas, da cultura pop, da educação e - acima de tudo - da ciência, pois é um discurso que simultaneamente instancia políticas em prol da popularização do ensino e aprendizagem de língua inglesa e se coloca como pano de fundo a leis antiestrangeirismo. Nessa linha, Gimenez (2013, p. 201) resume dois tipos de disseminação de influências: "1) a direta, pelo fluxo de ideias em redes sociais e políticas e 2) o patrocínio ou imposição de soluções por agendas multilaterais, como o Banco Mundial", a que Mainardes (2006, p. 51-2) acrescenta um terceiro: "os grupos e indivíduos que 'vendem' suas soluções no mercado político e acadêmico por meio de periódicos, livros, conferências e 'performances' de acadêmicos que viajam para vários lugares para expor suas ideias etc."

O segundo contexto - de produção do texto político - consiste na textualização dos discursos que instanciam as políticas em manifestações concretas: os textos políticos. Os textos produzidos frequentemente são de diferentes gêneros do discurso - textos legais e oficiais, comentários formais ou informais sobre os textos oficiais, vídeos etc. (MAINARDES, 2006, p. 52). Esses textos não são necessariamente coerentes e coesos, e de modo algum representam a finalização da política, pois são textos feitos para serem lidos, (re)criados e (re) configurados na prática social dos sujeitos endereçados pela política. A ideia

de que as políticas não são simplesmente implantadas como foram propostas torna explícita a existência de práticas de apropriação e/ou 
resistência que produzem efeitos que podem representar mudanças e transformações significativas na política original. No nível da prática, a abordagem do ciclo de políticas assume que os profissionais que atuam nas escolas exercem um papel ativo no processo de interpretação e reinterpretação das políticas (PAULILO, 2010, p. 491, grifos nossos).

O contexto de prática é ao que se referem os grifos da citação acima, pois é nele que a política está sujeita à interpretação e recriação, e no qual produz efeitos e consequências que podem representar mudanças e transformações significativas na proposta original, conforme formulada pelo(s) discurso(s) e texto(s) políticos. Para os autores referência da ACP, portanto, os profissionais que atuam no contexto de prática

não enfrentam os textos políticos como leitores ingênuos, eles vêm com suas histórias, experiências, valores e propósitos (...). Políticas serão interpretadas diferentemente uma vez que histórias, experiências, valores, propósitos e interesses são diversos. A questão é que os autores dos textos políticos não podem controlar os significados de seus textos. Partes podem ser rejeitadas, selecionadas, ignoradas, deliberadamente mal entendidas, réplicas podem ser superficiais etc. Além disso, interpretação é uma questão de disputa. Interpretações diferentes serão contestadas, uma vez que se relacionam com interesses diversos, uma ou outra interpretação predominará, embora desvios ou interpretações minoritárias possam ser importantes. (BOWE et al., 1992, p. 22 apud MAINARDES, 2006, p. 53)

Desse modo, investigar as políticas em sua integralidade implica pesquisar sujeitos sociais que atuam no aqui-e-agora de seus contextos, a partir de sentidos locais conjuntamente construídos e contingentes a suas práticas, com limitações e interesses que influenciam diretamente as políticas.

Por fim, há o contexto de resultados. Esses resultados são divididos em duas categorias: gerais e específicos, e relacionam-se diretamente com o impacto das políticas formuladas, textualizadas e (re)contextualizadas na prática social em duas instâncias: (1) nos cenários em que foram implementadas e em relação aos sujeitos a que foram endereçadas e (2) ao conjunto da sociedade, assim como ao conjunto global dos discursos (presentes em todo o ciclo, mas mais evidentes no contexto de influência e de produção do texto político) que instanciam e decorrem da política em questão.

Pode-se afirmar, a partir dessa perspectiva, que a política não deixa de ser discurso que se materializa superficialmente nas formas de textos, apesar de não se subsumir a isso; como tal, os leitores leem os textos políticos (e interpretam as políticas) de modo situado e singular, a partir de suas perspectivas históricas e sociais, de seus desígnios e planos pessoais, que se materializam em atitudes responsivas aos textos e discursos (BAKHTIN, 2010, p. 271-272). Portanto, do mesmo modo que não se pode afirmar que o autor de um texto é dono de seus sentidos, uma vez que estes serão construídos com o leitor, não se pode afirmar que os resultados de uma política são necessariamente aqueles planejados por quem as pensou, na medida em que os sujeitos que as vão reconstruir na prática social o farão a partir da interpretação que fizerem de leituras dos textos políticos.

Desse modo, como já dito, o IsF é uma política pública que foi primeiramente pensada para oferecer cursos de inglês de modo a capacitar os estudantes elegíveis ao CsF para viajarem ao exterior. Entretanto, na prática, há um número de outras implicações, ou efeitos, que são visíveis para todos os seus participantes, sendo a formação de professores, na perspectiva delineada e defendida na subseção seguinte, a mais cara para nós.

\subsection{Formação de professores}

Nossa década vem marcando uma profusão de iniciativas relacionadas à formação inicial e continuada de professores, como podemos constatar a partir de uma simples incursão no site do Ministério da Educação. ${ }^{6}$ Para citar alguns exemplos, há o Programa Institucional de Bolsa de Iniciação à Docência (PIBID), o Pacto Nacional pela Alfabetização na Idade Certa, o Pacto Nacional pelo Fortalecimento do Ensino Médio, e os mestrados profissionais para os professores da educação básica (como o PROFLETRAS e o PROFMAT). ${ }^{7}$ 
A existência simultânea de todos esses mecanismos de formação de professores, quer inicial ou continuada, aponta para uma realidade já captada pelo radar atento de Antônio Nóvoa (2009, p. 28), quando afirma que os anos 2000 parecem ter marcado a volta do olhar ao professor como forma de melhorar a educação, após décadas em que as pautas principais da educação estiveram relacionadas com questões técnico-metodológicas de gestão do espaço escolar e institucional.

Entretanto, essa volta ao professor e à sua formação nos coloca uma questão que não podemos ignorar: $o$ que é ser um bom professor? E a resposta a essa questão nos remete a uma nova pergunta, dela derivada: como formaremos esse bom professor? Evidentemente, as respostas a essas perguntas não são simples nem isentas de posicionamentos éticos, políticos, ideológicos e/ou teóricos. Ou seja, as possíveis respostas fatalmente têm de emergir de um comprometimento a um modo de se entender a história e a História, as relações sociais, a função do professor na sociedade (a que temos e, não menos importante, a que queremos), as complexas relações entre conhecimento e construção da cidadania, e a adesão a certas concepções de ensino e aprendizagem.

A recente literatura em formação de professores tem apontado duas possíveis tendências na resposta a essas perguntas: uma privilegia a reflexão sobre conhecimentos técnicos e outra sobre conhecimentos práticos. A primeira tendência entende que o professor necessita de conhecimentos técnicos e científicos generalizáveis, de modo a serem aplicáveis a uma diversidade de contextos (PÉREZ GÓMEZ, 1995) por generalização, como recomenda o paradigma positivista de ciência. A segunda propõe a necessidade de formarmos professores de modo eminentemente prático, isto é, a partir da vivência do trabalho docente nas comunidades de prática em que ele ocorre e em constante contato com pares (NÓVOA, 2009; SCHÖN, 2000); desse modo, o professor em formação pode construir um repertório de casos concretos, situados e particulares, que podem servir de referência para a tomada de decisões futuras em casos similares ou mesmo distintos. ${ }^{8}$

Em recente e notável trabalho, Costa (2013), a partir de um olhar etnográfico para um Instituto Cultural Brasileiro na capital de um país sul-americano, propõe um olhar atento ao que ocorre no dia a dia dos professores participantes de sua pesquisa: uma formação prá$x i c a,{ }^{9}$ por meio da participação em uma comunidade de prática. Dito de outro modo, os professores, nas suas interações diárias nos mais diversos espaços do instituto, debatem problemas situados e contingentes que, muitas vezes, são conjuntamente pensados a partir do recurso à teoria e ao conceito. Ou seja, não há separação entre teoria e prática; há, sim, uma prática da qual emergem situações contingentes que demandam reflexões de várias ordens, inclusive teóricas e conceituais, que, por um lado, não são generalizáveis, no sentido positivista do termo, mas, por outro, não caem num buraco negro histórico e nem são esquecidas, pois servem como base para situações futuras.

Nesse sentido, os achados etnográficos de Costa (2013) incidem na direção do que tem sido amplamente defendido por Nóvoa (2009, p. 28), quando este anota que a formação de professores deve passar por dentro da profissão. Nas palavras do autor:

A formação de professores deve assumir uma forte componente práxica, centrada na aprendizagem dos alunos e no estudo de casos concretos, tendo como referência o trabalho escolar... Não se trata de adoptar uma qualquer deriva praticista e, muito menos, de acolher as tendências anti-intelectuais na formação de professores (Nóvoa, 2008). Trata-se, sim, de abandonar a ideia que a profissão docente se define, primordialmente, pela capacidade de transmitir um determinado saber. É esta concepção que tem levado às intermináveis discussões entre "republicanos", que apenas se interessariam pelos conteúdos científicos, e "pedagogos", que colocariam os métodos de ensino acima de tudo o resto (adopta-se aqui a divisão entre "republicanos" e "pedagogos" habitual nas polémicas educativas em França - ver a tese de doutoramento de Alain Trouvé, 2006). Não. O que caracteriza a profissão docente é um lugar outro, um terceiro lugar, no qual as práticas são investidas do ponto de vista teórico e metodológico, dando origem à construção de um conhecimento profissional docente. (NÓVOA, 2009, p. 32) 
O referencial teórico aqui adotado, de certo modo, foi proposto pelos próprios dados que vimos obtendo e em nossas observações ao longo dos últimos meses, visto que passamos a entender que o que tínhamos em mão era uma formação de professores a partir do trabalho docente e da reflexão teórico-prática sobre este. Essa percepção surgiu ao notarmos que a formação de professores emergiu como um efeito positivo do programa, posto que não esteja diretamente explícito nos objetivos centrais do IsF e deu as tintas com as quais viríamos a construir nosso mosaico teórico.

Por fim, podemos resumir a questão de formação de professores, sob nossa ótica, com as seguintes asserções: (1) acontece a partir do trabalho docente e em contato com pares; (2) não é um conhecimento técnico no sentido positivista do termo, pois as aprendizagens que ocorrem, em geral, não podem ser generalizadas (removidas de um contexto e empregadas em outro), pois são contingentes e contextuais; (3) porém, essas aprendizagens, em seu conjunto, ajudam a construir um repertório que pode servir de base para a tomada de decisão futura, no sentido de (re)produção e (re) criação de soluções de modo reflexivo e sensível a novos contextos; (4) nesse sentido, a consciência sobre os processos de reflexão-na-ação propiciados pelo trabalho docente e interação com pares são importantes para que se gere inteligibilidade sobre a prática, de modo a subsidiar ação futura.

\section{Cenário de pesquisa: o NucLi-UFRGS}

O NucLi-UFRGS é, no momento da redação deste texto (janeiro/2015), o maior do Brasil. Tem capacidade de atender a até 1.100 alunos simultaneamente, e conta com o trabalho de 20 professores, cinco auxiliares administrativos e quatro English Teaching Assistants (ETAs)..$^{10} \mathrm{O}$ quadro sinóptico abaixo resume os números dos primeiros sete ciclos, todos em 2014, com os números de turmas ofertadas, turmas confirmadas $\mathrm{e}$ alunos efetivamente atendidos.
TABELA 1: Turmas ofertadas IsF-UFRGS em 2014

\begin{tabular}{|l|l|l|l|}
\hline $\begin{array}{l}\text { Resumo } \\
\text { das ofertas }\end{array}$ & $\begin{array}{l}\text { Turmas } \\
\text { ofertadas }\end{array}$ & $\begin{array}{l}\text { Turmas } \\
\text { confirmadas }\end{array}$ & $\begin{array}{l}\text { Alunos } \\
\text { confirmados }\end{array}$ \\
\hline Oferta 1 & 60 & 23 & 321 \\
\hline Oferta 2 & 40 & 38 & 519 \\
\hline Oferta 3 & 10 & 10 & 186 \\
\hline Oferta 4 & 10 & 10 & 194 \\
\hline Oferta 5 & 22 & 21 & 363 \\
\hline Oferta 6 & 52 & 33 & 548 \\
\hline Oferta 7 & 27 & 23 & 399 \\
\hline TOTAL & 221 & 158 & 2.530 \\
\hline
\end{tabular}

Números de turmas e alunos. Fonte: Comitê Gestor IsF/ MEC-SESU

Uma questão que tem se demonstrado peculiar em relação à nossa expectativa é que os cursos preparatórios para exames de proficiência tiveram uma procura muito baixa, enquanto os cursos de língua de níveis mais básicos ${ }^{11}$ constituíram-se a preferência do maior número de alunos. Entretanto, os dois mapeamentos do nível de proficiência de nosso público, o nivelamento no curso online MEO e o resultado dos 5.300 exames TOEFL ITP aplicados no primeiro semestre de 2014, apontam que a maioria está entre $\mathrm{B} 1$ e $\mathrm{B} 2^{12}$ (de acordo com o Quadro Comum Europeu). O quadro abaixo resume a situação dos alunos da UFRGS no MEO:

TABELA 2: Alunos UFRGS ativos no MEO

\begin{tabular}{|l|l|l|l|l|}
\hline & $\begin{array}{l}\text { Alunos } \\
\text { matriculados }\end{array}$ & $\begin{array}{l}\text { Alunos } \\
\text { nível } \\
\mathbf{2 - 5}\end{array}$ & $\begin{array}{l}\text { Alu- } \\
\text { nos } \\
\text { nível 1 }\end{array}$ & $\begin{array}{l}\text { Alunos } \\
\text { ainda } \\
\text { inativos }\end{array}$ \\
\hline $\begin{array}{l}\text { Dezembro } \\
2013\end{array}$ & 7484 & 4.563 & 1.204 & 1.717 \\
\hline $\begin{array}{l}\text { Outubro } \\
2014\end{array}$ & 13.362 & 8.129 & 1.792 & 3.441 \\
\hline
\end{tabular}

Fonte: Comitê Gestor IsF/MEC-SESU

O gráfico abaixo resume, de modo mais específico, os resultados dos alunos e seus respectivos níveis atribuídos: 


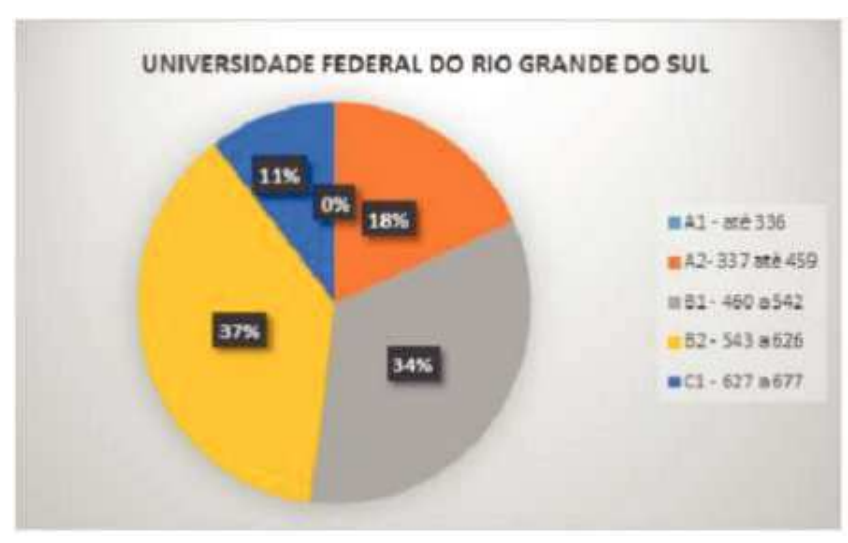

Figura 1: perfil de proficiência linguística dos alunos UFRGS

Como o gráfico aponta, há mais de 70 por cento de predominância de alunos de nível B1 e B2. Além disso, há uma fatia considerável de alunos do nível máximo avaliado pelo exame, $\mathrm{C} 1$, e nenhum aluno no nível mais básico. Importante ressaltar que se trata de uma amostra tendenciosa, pois os participantes não foram escolhidos aleatoriamente seguindo princípios sociais pré-estabelecidos. Além disso, o exame não se propõe a medir o nível C2 e é pouco eficaz para diagnosticar alunos de nível A1. ${ }^{13}$ De modo geral, ainda que o nível dos alunos do NucLi-UFRGS não seja central para a nossa análise, pareceu-nos interessante explicitar o perfil linguístico dos alunos desses professores-bolsistas que são alvo de nossa investigação.

Em suma, o NucLi-UFRGS, no momento de redação deste texto, era o maior do país, o que significa que os professores-bolsistas que nos serviram de participantes de pesquisa tinham um grande número de alunos e de pares com quem interagir, diferentemente do que acontece em diversos outros cenários em que o professor de inglês encontra-se isolado de seus pares. Além disso, o fato de uma grande parcela dos alunos do NucLi-UFRGS serem de nível intermediário ou intermediário-superior (B1 e B2) implica, além do desafio pedagógico, um desafio linguístico.

\section{Metodologia}

Este trabalho está inserido na tradição de pesquisa qualitativa de cunho interpretativo (MASON, 1996) e tem como objetivos: (1) identificar, conforme a percepção dos professores-bolsistas do NucLi-UFRGS, as ati- vidades que realizam enquanto docentes do programa, (2) analisar quais atividades esses professores-bolsistas consideram mais relevantes para seu processo de formação, (3) especificar a natureza dessas atividades e (4) relacionar nosso percurso teórico-conceitual no tocante à formação de professores aos entendimentos formulados pelos professores-bolsistas.

Para os fins deste texto, 12 professores do NucLi UFRGS foram submetidos a um questionário online feito através do Google Forms e respondido por eles durante uma das reuniões semanais. O questionário continha as seguintes perguntas:

1. Quais atividades você já realizou como professor do IsF?

2. Dentre essas, quais você ressaltaria como as que mais lhe propiciaram aprendizagens?

3. No âmbito das aprendizagens elencadas acima, quais você destacaria como mais relevantes para sua formação como professor/a de inglês? Por quê? ${ }^{14}$

Os professores não precisavam se identificar, de modo que pudessem se sentir mais confortáveis para responder sem o receio de que seriam avaliados por suas coordenadoras. O número de linhas para a resposta era livre e eles tiveram aproximadamente 30 minutos para responderem às três questões. As respostas foram numeradas e editadas de modo a corrigir pequenos erros de digitação e linguagem, que creditamos à rapidez da digitação e ao pouco tempo que os participantes tiveram para responder ao questionário. Por fim, as respostas foram tratadas e categorizadas de modo a serem de mais fácil apresentação para o leitor a partir de critérios específicos estabelecidos a posterióri, que serão explicitados na análise. As respostas cujas formulações creditamos como muito similares foram agrupadas em torno de apenas uma resposta, a que julgamos mais representativa da mediana das demais e, por conseguinte, mais prototípica da formulação. ${ }^{15}$ 


\section{5. "Na prática temos que lidar com questões que nem mesmo a mais completa preparação teórica nos responde e temos a possibilidade de ensinar $e$ aprender", ou breve análise dos dados}

Analisando o conjunto de respostas à primeira pergunta, podemos notar que as respostas são bastante parecidas, sendo muito comum respostas idênticas. $\mathrm{O}$ quadro abaixo mostra um resumo das atividades mencionadas pelos professores:

- Quais atividades você já realizou como professor do IsF? 16

1. Dar aulas

2. Preparar aulas

3. Preparar palestras

4. Ministrar palestras

5. Participar de reuniões

6. Preparação de oficinas sobre aprendizagem de inglês (reading, listening, movies, music, etc.)

7. Escrita de material para a página do Facebook

8. Escrita de relatórios

9. Atendimento de alunos $\mathrm{MEO}$

10. Elaboração de material didático

11. Orientação aos alunos na escrita do Statement of Purpose

Poderíamos categorizar as atividades em três grupos: (1) diretamente vinculadas ao trabalho docente; (2) relacionadas ao trabalho docente; (3) não relacionadas ao trabalho docente; as repostas 1, 2, 3, 4,6 e 10 estariam na primeira categoria; as respostas 5, 8, 9 e 11 na segunda; e a resposta 7 na terceira. Do conjunto de respostas, podemos ver que a maioria dos participantes salientaram atividades diretamente vinculadas ou ao menos relacionadas ao trabalho docente. Isso não é em nada surpreendente, posto que estão inseridos em um programa no qual devem efetivamente atuar como professores, acarretando, assim, as funções inerentes ao ofício.

A segunda pergunta solicita que os professores, desde sua perspectiva, elenquem as atividades que tenham considerado aquelas com que mais tenham aprendido. O quadro abaixo resume as respostas, também evitando repetições.

- Dentre essas, quais você ressaltaria como as que mais lhe propiciaram aprendizagens?

1. Participar das reuniões pedagógicas

2. Dar aulas

3. Planejar aulas

4. Planejar oficinas/palestras

5. Planejar aulas em grupo

6. Discutir textos nas reuniões pedagógicas

Novamente os professores selecionaram atividades diretamente vinculadas ou ao menos relacionadas à profissão de professor: como planejar (resposta 3) e lecionar aulas oficinas e palestras (respostas 3 e 4), bem como atividades colaborativas relacionadas à reflexão sobre as aulas, tanto de modo mais voltado à prática pedagógica, como é o caso da resposta número 5 , como à reflexão sobre essa prática, realizado em conjunto pelo grupo, como é o caso das respostas de números 1 e 6 . Isso se alinha às asserções com que resumimos a seção que delineia nossas adesões teórico-conceituais acerca da formação docente: aprende-se a ser professor a partir da prática docente e da reflexão sobre essa prática. (SCHÖN, 2000)Nesse sentido, pode-se afirmar que os participantes de pesquisa, em suas respostas, parecem partilhar desse entendimento que usamos para nortear nossa compreensão sobre formação docente.

Todos os 12 participantes mencionaram as Reuniões Pedagógicas. Podemos especular que essa escolha deva-se a uma peculiaridade: é o momento em que as questões emergentes da prática dos professores podem ser discutidas em grande grupo, com a mediação de pares muito mais experientes: as coordenadoras do IsF-UFRGS. Isto é, a reunião também é um momento de recurso à teoria, à literatura da área e ao conceito, pois nas reuniões ocorrem discussões sobre textos escolhidos pelas coordenadoras para servirem de subsídio tanto nas discussões de grande grupo, como nas preparações de aula em pequenos grupos e individualmente, e na atuação de cada um na sala de aula. Desse modo, a menção às reuniões pode ser correlacionada à 
geração conjunta de inteligibilidades sobre problemas específicos de sala de aula, ao recurso ao conceito e à teoria para iluminar esses problemas, o que é sugerido em várias das respostas.

Na última pergunta, os professores puderam explicitar os motivos pelos quais escolheram determinadas atividades em detrimento de outras, relacionando as atividades com entendimentos acerca de sua formação que parecem estar articuladas com o enfoque teórico-conceitual que optamos para dar conta desses dados.

Todas as repostas sugerem que os três eixos do que chamamos de trabalho docente sejam percebidos pelos professores-bolsistas como relevantes para sua formação como docentes: (1) prática docente, (2) reflexão sobre a prática e (3) produção de inteligibilidade para subsidiar prática futura.

- No âmbito das aprendizagens elencadas acima, quais dessas você destacaria como mais relevantes para sua formação como professor/a de inglês? Por quê? ${ }^{17}$

1. As reuniões pedagógicas, quando possuem foco pedagógico, pois possibilitam pensar nas atividades docentes. Ministrar aulas, pois possibilitam colocar em prática uma série de aprendizados adquiridos no decorrer da graduação.

2. A preparação de palestras/ oficinas, pelo fato de termos que selecionar material, adequá-lo às necessidades do público-alvo e apresentar o conteúdo de forma didática e atraente.

3. Ambas (preparar e ministrar aulas). Tanto o planejamento de aulas, pois é o momento em que me preparo, quanto dar aula, pois muitas vezes me deparo com situações que fogem do que foi planejado.

4. As reuniões porque aprendi coisas relacionadas à burocracia do programa e preparar aulas porque pude discutir atividades com meus colegas e trocar experiências sobre dar aula e coisas que funcionam ou não em sala de aula.
5. As reuniões, pois conseguimos discutir questões relevantes para o ensino de inglês dentro do contexto em que estamos inseridos.

6. A experiência em sala de aula e conhecimento teórico (reuniões pedagógicas). Também acho importante a troca de atividades entre os colegas.

7. Nas palestras informativas e sobre o IELTS e agora como professora em sala de aula, aprendo muito sobre preparação de material didático, mesmo que eu use um livro didático no curso que ministro, tenho que preparar a aula pensando nas possíveis dúvidas, pensando em materiais extra que possam ajudar os alunos, qual "approach" devo fazer para cada exercício. Nas palestras, também tive que pesquisar bastante e me apropriar daquilo que eu devia apresentar, o que fez eu aprender também.

8. Acho que participar da elaboração de uma súmula de disciplina como fizemos para o TOEFL iBT foi bem proveitoso, pois foi uma experiência nova num ambiente novo. Sendo que considero este tipo de curso uma nova tendência de mercado o que nos valoriza como profissionais. Poderia citar também a experiência como aplicador TOEFL.

9. O planejamento das aulas e ministrá-las posteriormente. É uma aprendizagem fundamental, e já noto que de aula em aula as coisas vão melhorando, em decorrência da prática e das experiências prévias.

10. Realmente, o que parece ser mais relevante no meu desenvolvimento com professor de inglês, e principalmente como professor, é ter que lidar com o contexto de ensino. Não posso ser um bom professor se não sei enfrentar adequadamente as dificuldades impostas pelo contexto de cada aula e, também, ser capaz de elaborar soluções para cada problema que surgir.

11. As monitorias e as aulas presenciais são as que trazem maior conhecimento. Na prática temos que 
lidar com questões que nem mesmo a mais completa preparação teórica nos responde e temos a possibilidade de ensinar e aprender, com os alunos. Depois disso são as aulas palestras e as reuniões em si. Mas sem dúvida a maior fonte de aprendizagem são as aulas.

12. A prática da sala de aula certamente é a atividade que mais contribui para a formação docente, estar envolvido com os alunos, no processo de ensino e aprendizagem. As reuniões e acompanhamento das coordenadoras são essenciais porque através destes podemos garantir a qualidade das aulas.

As respostas 1, 2, 3, 4, 5, 6, 7, 9 e 11 estão diretamente relacionadas ora a aspectos de preparação de aulas, elaboração de materiais didáticos e preparação de palestras, ora a seu ensino e apresentação a alunos (quer seja dos cursos, quer das palestras). Ou seja, aspectos da prática docente, como preparar e ministrar aulas e palestras, são indicados pelos participantes como fontes de aprendizagem e formação.

Nas respostas 1, 5 e 12, aspectos vinculados à reflexão sobre aspectos inerentes à prática docente são salientados. As reuniões pedagógicas, como não é de se espantar, parecem ser o momento institucionalizado para essa reflexão sobre questões teórico-conceituais e também para a qualificação da compreensão de questões emergentes da prática e a ela inerentes.

Gostaríamos de salientar, contudo, as respostas 2, 3, 9 e 10, pois elas parecem ser reveladoras da relação reflexiva com a prática que entendemos intrínseca à participação em um programa como os IsF. Nessas respostas, pode-se argumentar, os professores articulam suas experiências ao aprimoramento em sua competências de adequar o material ao público alvo, resolver questões não antevistas no planejamento, melhorar práticas futuras a partir das experiências, elaborar soluções a cada problema que surgir e lidar adequadamente com questões práticas que nem a mais completa preparação teórica dê conta. Ora, o que não são essas competências se não aquelas que esperamos de professores reflexivos?

Portanto, os dados relativos aos professores, em convergência com a compreensão de que são a prática social e os cenários da vida cotidiana que dão vida às políticas públicas (BALL, 1994), revelam o potencial do programa IsF para a formação de professores. Esse resultado, ainda que preliminar, evidencia a riqueza desse contexto e sugere que trabalhos com formação docente devem partir da vivência do trabalho docente nas comunidades de prática em que ele ocorre e em constante contato com pares (NÓVOA, 2009; SCHÖN, 2000).

\section{Considerações finais}

A partir do que os dados expõem, de modo ainda preliminar, acreditamos que os processos de formação de professores no NucLi-UFRGS vêm se aproximando, de certo modo, à proposta que Nóvoa $(2009$, p. 34) faz a partir da observação de alunos de medicina em uma escola hospital. Nas palavras do autor:

tive a oportunidade, recentemente, de acompanhar um grupo de estudantes e professores de Medicina num hospital universitário. Do que pude observar, quero chamar a atenção para quatro aspectos: i) o modo como formação se realiza a partir da observação, do estudo e da análise de cada caso; ii) a identificação de aspectos a necessitarem de aprofundamentos teóricos, designadamente quanto à possibilidade de distintas abordagens de uma mesma situação; iii) a existência de uma reflexão conjunta, sem confundir os papéis de cada um (chefe da equipa, médicos, internos, estagiários, etc.), mas procurando mobilizar um conhecimento pertinente; iv) a preocupação com questões relacionadas com o funcionamento dos serviços hospitalares e a necessidade de introduzir melhorias de diversa ordem. Estamos perante um modelo que pode servir de inspiração para a formação de professores. Os quatro aspectos acima mencionados encerram quatro lições importantes. Em primeiro lugar, a referência sistemática a casos concretos, e o desejo de encontrar soluções que permitam resolvê-los. Estes casos são "práticos", mas só podem ser resolvidos através de uma análise que, partindo deles, mobiliza conhecimentos teóricos. A formação de professores ganharia muito se se organizasse, preferentemente, em torno de situações concretas, de insucesso escolar, de problemas escolares ou de programas de acção educativa. (NÓVOA , 2009, p. 34) 
Nos dados, podemos notar que as respostas dos professores-alunos estão eminentemente vinculadas a sua atuação em sala de aula. Todos eles, de modo mais ou menos direto, citam a atuação em sala de aula como sua maior fonte de aprendizagem. Além disso, muitos deles citam a preparação de aulas, palestras e ementas de curso como uma das atividades centrais no seu processo de desenvolvimento como docente. Vários outros também mencionam a discussão dos textos escolhidos para as reuniões pedagógicas, que tratam de problemas relacionados ao tipo de aula que dão. Isso, acreditamos, coaduna-se, de certo modo, com o compromisso de se trazer a profissão e o trabalho docente para dentro da formação de professores, e desterritorializa a já gasta dicotomia teoria-prática, como apontado por Nóvoa, para um fazer em que teoria e prática se integram a partir de experiências concretas vivenciadas desde dentro do trabalho docente. Nesse sentido, pois, há o recurso ao conceito, ao texto e à prática, instanciados pelos casos concretos vivenciados no cotidiano do trabalho docente.

Assim, acreditamos que o IsF possa ser um lugar promissor de formação inicial ou da continuada; um terreno fértil para a formação do professor reflexivo e crítico; um contexto de aprendizagens sobre os quefazeres da nossa profissão; um contexto a mais para os cursos de licenciatura nas universidades formarem futuros profissionais mais conscientes de seus fazeres; um contexto a mais para os professores aprenderem a ensinar a partir e dentro de seu contexto de prática. Nesse sentido, nossa reflexão vai ao encontro do que tem proposto o educador António Nóvoa, propondo que o IsF pode ser uma das tantas possíveis vias para que a formação teórica e conceitual do professor faça sentido para além do conceito, como ocorre na formação dos médicos.

Este estudo, ao mesmo tempo em que contribui para o redimensionamento de uma política pública brasileira na medida em que revela o potencial do programa IsF para a área de formação de professores, apresenta limitações em razão de sua característica exploratória. Os dados, advindos de uma única fonte, quer seja, um questionário, demonstram certa fragilidade. Reconhecemos a necessidade de um estudo com mais fontes de dados e, sobretudo, com dados etnográficos gerados diretamente no setting, que façam descrição densa e análise das atividades que constroem a prática do NucLi-UFRGS do qual o questionário apenas representa a ponta do iceberg. Entendemos, entretanto, que a riqueza deste texto está no destacamento do tema para o cenário da formação docente. Talvez a boa nova é que esta pesquisa já está em curso, e poderemos, em breve, retomar esta conversa uma oitava acima.

\section{Notas}

1. Em 14 de novembro de 2014, através da Portaria N973 publicada no DOU (p.11, seção 1), foi instituído o Programa Idiomas sem Fronteiras, que amplia o Inglês sem Fronteiras tanto no número de línguas a serem oferecidas quanto na sua atuação, que busca agora, além de outros aspectos, "fortalecer o ensino de idiomas no país, incluindo o da língua portuguesa, e, no exterior, o da língua portuguesa e da cultura brasileira."

2. E não necessariamente para o mercado de trabalho. O termo "Trabalho" aqui está mais aliado a um entendimento marxista da atividade de intervir no mundo em que vivemos do que na venda da nossa força produtiva.

3. Termo utilizado por Nóvoa (2009, p. 29).

4. O grupo de professores bolsistas conta com uma aluna de pós-graduação (doutorado) e dezenove graduandos e graduandas de diversas etapas, sendo que a maioria deles entre o meio e o fim do curso de graduação em letras inglês (ou inglês- português). Ou seja, é possível afirmar que na maioria dos casos trata-se de formação inicial de professores.

5. Embora Ball (1994) formule também o contexto de influência política, este não será foco do presente trabalho e, portanto, não será descrito de modo mais pormenorizado.

6. http://www.mec.gov.br/

7. Quando da redação deste texto, em março de 2015.

8. Neste caso, o foco não é na possibilidade de se generalizar técnicas abstratas, mas, sim, de construir a capacidade de se (re)criar e (re)produzir soluções anteriores, com sensibilidade, criatividade e reflexividades.

9. Termos propostos por nós a partir da leitura do trabalho sob a lente da terminologia proposta por Nóvoa (2009). Significa basicamente que, nos dados do pesquisador, há uma aparente superação do falacioso binômio teoria $\mathrm{x}$ prática, na medida em que, na atuação dos professores e em suas interações 
cotidianas no instituto, problemas de ordem prática ganham contornos reflexivos práticos ou teóricotécnicos, dependendo da contingência sendo tratada.

10. O Programa English Teaching Assistants (ETAs), ou programa de Professores Assistentes de Língua Inglesa é uma parceria CAPES/ Fulbright que seleciona e patrocina bolsistas para atuarem em universidades brasileiras com o intuito de atuar nos programas deno desenvolvimento da proficiência em língua inglesa do público academico.

11. Voltados ao MEO 2 e 3. http://www.myenglishonline. com.br/. É a plataforma online e gratuita escolhida pelo MEC para o nivelamento dos estudantes e como mecanismo de autoestudo, para estudantes de IES públicas e estudantes de IES privadas que tenham atingido 600 pontos no ENEM. O MEO é dividido em 5 níveis, sendo nível 1 iniciante e nível 5 avançado.

12. O quadro comum europeu é dividido em A1 e A2 (iniciante e básico), B1 e B2 (intermediário e usuário independente), e C1 e C2 (proficiência operativa eficaz e domínio pleno), conforme http://www.coe.int/t/dg4/ linguistic/source/framework_en.pdf.

13. Isso tem saltado ao olhos, na medida em que o número de alunos classificados como A1 pelo exame é proporcionalmente menor do que pelo teste de nivelamento do MEO. $O$ fato de não haver mais turmas de nível A1 na maioria dos NucLi após os TOEFL ITP ter substituído o MEO como mecanismo de nivelamento e porta de entrada aos cursos presenciais do IsF parece ratificar esse entendimento

14. As perguntas podem ser visualizadas em https://docs. google.com/forms/d/1jwj2PXP8hFko8fHczR4qxtjyye FJ8LkridzWm_OlkmA/edit

15. As respostas podem ser visualizadas acessando https://docs.google.com/spreadsheet/ ccc?key=0AuSjOg48RG_-dGNnN2pHV2hlNFNUQz NUdjljOXNZbnc\&usp=drive_web\#gid $=0$

16. Respostas apresentadas da mais frequente para a menos frequente.

17. Respostas apresentadas na ordem em que estão na tabela do Google Forms.

\section{Referências}

ABREU E LIMA, D. O programa Inglês sem Fronteiras e a inserção das línguas nas políticas institucionais. In: Public policies in the teaching of languages in Brazil. ABRAPUI, IV, Maceió-AL, 2014 (conferência em mesa-redonda).

AUGUSTO-NAVARRO, E. H.; GATTOLIN, S. R. B. Transpondo fronteiras na formação de professores de inglês. In: Formação de professores, ensino de inglês e processos de Internacionalização no programa Inglês sem Fronteiras. ABRAPUI, IV, Maceió-AL, 2014 (conferência em mesa-redonda).

BAKHTIN, M. Estética da criação verbal. Trad. Paulo Bezerra. São Paulo: Martins Fontes, 2010 .

BALL, S. J. Education reform: a critical and post structural approach. Buckingham: Open University Press, 1994.

BOWE, R.; BALL, S.; GOLD, A. Reforming education \& changing schools: case studies in policy sociology. London: Routledge, 1992.

COSTA, E. C. Práticas de formação de professores de Português Língua Adicional em um instituto cultural brasileiro no exterior. Porto Alegre: PPGLET UFRGS, Dissertação de Mestrado, 2013.

DELLAGNELO, A. Aprendizagem e desenvolvimento de docentes: a percepção de dois professores iniciantes. In: Formação de professores, ensino de inglês e processos de Internacionalização no programa Inglês sem Fronteiras. ABRAPUI, IV, Maceió-AL, 2014 (conferência em mesa-redonda).

GIDDENS, A. As consequências da modernidade. São Paulo: Editora Unesp, 1991.

GIMENEZ, T. A ausência de políticas para o ensino de língua inglesa nos anos iniciais no Brasil. In NICOLAIDES, C. ET AL. (orgs.). Política e Políticas Linguísticas. Campinas: Pontes, 2013, 199-218.

MAINARDES, J. Abordagem do ciclo de políticas: uma contribuição para a análise de políticas educacionais. Educação e Sociedade, Campinas, v. 27, n. 94, 47-69, 2006.

MASON, J. (1996). Qualitative Researching. Londres: Sage.

NÓVOA, A. Professores: imagens do futuro presente. Lisboa: Educa, 2009. (PDF)

PAULILO, A. L. A pesquisa em políticas públicas de educação numa perspectiva histórica. In: Revista Brasileira de Estudos Pedagógicos, Brasília, v. 91, n. 229, set./dez. 2010, 481-510.

PERÉZ GOMEZ, O Pensamento prático do professor: a formação do professor como um profissional reflexivo. In. NÓVOA, A. (org.). Os professores e sua formação. 2 ed. Lisboa: Dom Quixote, 1995, 93-114.

SARMENTO, S; KIRSCH, W. Inglês sem Fronteiras na UFRGS. In Encontro Nacional do Projeto Novos Letramentos, 5a Edição. São Paulo, SP: USP, 2014a.

SARMENTO, S.; KIRSCH, W. O Contexto de Prática do NucLi UFRGS: eventos de formação de professores. In: Formação de professores, ensino de inglês e processos de Internacionalização no programa Inglês sem Fronteiras. ABRAPUI, IV, Maceió-AL, 2014b (conferência em mesa-redonda). 
SCHÖN, D. Educando o profissional reflexivo: um novo design para o ensino e aprendizagem. Porto Alegre: ARTMED, 2000.

WELP, A. K. S.; SARMENTO, S.; KIRSCH, W. A construção da identidade do professor no Programa Inglês sem Fronteiras. In: Public policies in the teaching of languages in Brazil. ABRAPUI, IV, Maceió-AL, 2014 (conferência em mesa-redonda).

WENGER. E. Communities of Practice: Learning, Meaning, and Identity. Cambridge, UK: Cambridge University Press, 2000.

Recebido em: 03/01/2015

Aceito em: 22/02/2015 